\title{
TITLE OBSERVATIONS ON FIELD-EMISSION ELECTRONS FROM THE LOS ALAMOS FEL PHOTOINJECTUR
}

AUTHOR(S) Alex H. Lumpk in

SUbmitied to Proceeding;, 1991 Particle Accelerator Conference (PAC) Mny 6-9. 1991

\section{DISCLAIMEK}

Thin rep irt was prepured as un account of wort amonmored by un agency of the Uniled Sitales Government. Neither the Uniled Sistes (iovernment nor uny agancy the resf, nor uny of their employees. maken any warranty, expreas or implied, or annumes any legal liability of renponnoibility for the accuracy. completeness, or unefulness of any information, apparalus, product, or

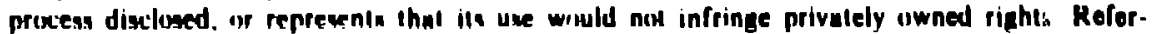

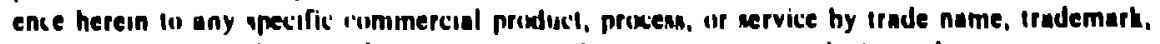
manufacturer, or otherwise does not leceswarily conntitute or imply itn andorsement, recom. mendalion, of fovorring hy the Unilod Sialen (iovernment o- any agency thereuf. The viewn and opinisinn of authors expremed herein do nor necensarty siate or reflect thuse of the Inited Situten (iovernment of any agencis theroul 


\title{
OBSERVATIONS ON FIELD-EMISSION ELECTRONS FROM THE LOS ALAMOS FEL PHOTOINJECTOR*
}

\author{
Nex H. Lumpkin \\ Physics Division \\ Los Alamos Natlonal Laboratory \\ Los Alamos, NM 81545 USA
}

\begin{abstract}
A background source of electrons from the photoelectric injector (PEI) of the Los Alamos FEL experiment has been identified. This source is present without the drive laser irradiation and when the of power is applied to the injector accelerator. Using intensified cameras and a synchroscan streak camera, these electrons have been imaged via optical transition radiation and Cherenkov radiation and characterized. The basic questions of location (photocathode), timing ( -40 to $90^{\circ}$ of the RF cycle), magnitude ( $2.2 \mathrm{nC}$ per $\mu 5$ of $\mathrm{rf}$ power at $26 \mathrm{MV} / \mathrm{m}$ at the photocathode), and parameter sensitivity (accelerator A field's duration and magnitude) have been answered. The properties are consistent with a field-emission mechanism.
\end{abstract}

\section{INTRODUCTION}

The Los Alamos FEL facility incorporates a phoroelectric injector (PEI) as a source of lower.istance electrons [1]. During the initial accelerator commissioning phase for beam energies of 14$17 \mathrm{MeV}$, electrons were accelerated, transported. and detected even when the PEI drive laser beam was blocked and only the RF power was on. This low power beam was initially detected with $x$-ray detectors and intensified television cameras that viewed intercepting beam-profile screens [2]. Using optical transition radiation (OTR) and Cherenkov radiation (CR) conversion mechantisms, the electron beam information was converted into visible light that was recorded by the intensified cameras and synchroscan streak camera, zespectively. Several iransport conditions were then used to image the background source and determine its location, spatial extent, timing, and parameter sensitivity. The characterizations led to the identification of the CaK $2 \mathrm{Sb}$ photocathode material as the source and field emission as the nuost probable mechanism. These results are some of the first 10

- Work supported by the US Department of Defonse under the auspices of the US Department of Energy. be reported from a high quantum efficiency (QE) photocathose/photoin jector.

\section{EXPERIMENTAL PROCEDURES}

The commissioning experiments begall in the summer of 1989 and ended in May 1990. The beamline diagnostics used for the majority of this time are schematically shown in Fig. 1 . No intercepting diagnostics or even wall current monitors (WCM) were allowed by the designers in the beamline until after the second accelerator tank. The electrons were transported about $7 \mathrm{~m}$ from the photocathode to the front-surface, aluminized fused-silica screen at position $\# 3$. The screen was oriented at $45^{\circ}$ to the beam direction so that OTR was viewed at $90^{\circ}$ to the beam direction and $C R$ was viewed at $46^{\circ}$ to the downstream beam direction. The beam position and profile were determined from the front surface (OTR) source and the $C R$ from the fused silica substrate was optically relayed to a synchroscan streak camera several meters away from this screen. The Hamamatsu C1587 streak camera was phase-locked to the $108.3 \mathrm{MHz}$ refererce frequency, which is a subharmonic of the master $1300 \mathrm{MHz}$ accelerator frequency. This technique allows the synchronous summing or integration of signals from many micropulses with relatively low jitter, 4 ps (FWHM), and reasonable temporal resolution, 5 ps (FW'HM). In the case of this low current source we integrated the whole if macropulse time at the 108.3 MHz repetition frequency [3].

\section{EXPERIMENTAL OBSERVATIONS}

As reported enrlier [3] there was a strong dependence of the background source intensity on the photoinjector accelerator (A) field amplitude and duration. Starting at $26 \mathrm{MV} / \mathrm{m}$, $20 \%$ reduction in field resulted in a factor of 5 decrease in the box-averase penk intensity of the rield-emission image. Under some conditions a single lasersenerared micropulse was comparable to the "iies.s emission" electrons from about $50 \mu \mathrm{s}$ of if power. A synchroscan streak image exhibited Iriplet temporal structure, which was altributed to a 


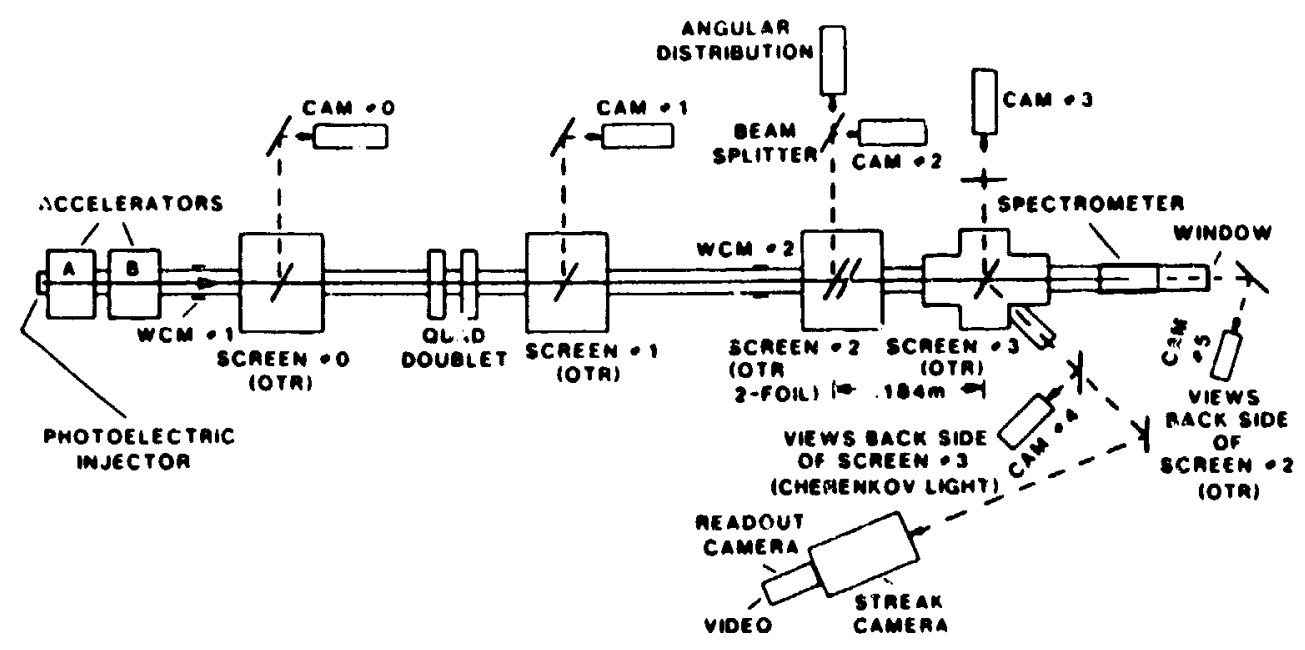

Fig. 1. Schematic of the accelerator beamline and diagnostics.

successful transport of electrons on only part of the of phase, ihe partial sampling by the streak camera's entrance slit of the Cherenkov image, and the overlap of two pairs of time doublets via the display of deflections from both sides of the 108$\mathrm{MHz}$ if deflection in the streak camera. The latter effect was further pro $n$ when a charise of $4 \dot{2}$ ps on the Narda phase shifter in the lin: between the if source and the streak's synchroscan input moved the doublets in opposite "time directions."

Figure 2 shows the simultaneous imaging of PEI and field-emission injector (FEI) electrons with the synchroscan-streak camera. In this case, the drive-laser phase was at $20^{\circ}$ to zero if phase, and the FE electrons appear about 30 ps later and

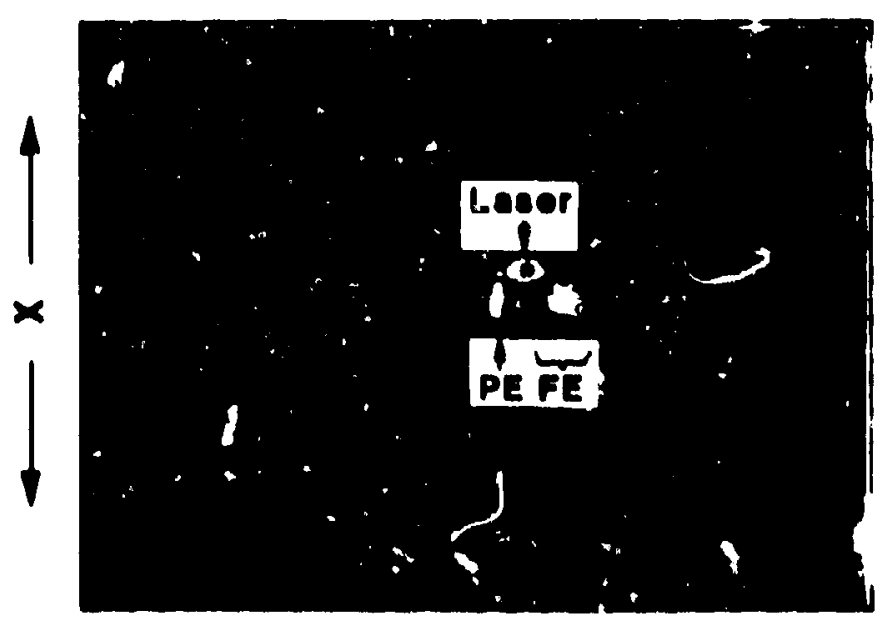

TIME (po)

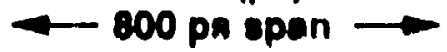

Fig. 2. "Simultaneous" synchroscan image of the drive laser, (PE) and FE sources. extend for $\sim 30$ to 40 ps (there is, thus, a several percent-energy spread). Due to transit-time effects in the first cell, the EE electron: can be generated from 40 to $90^{\circ}$ of phase and arrive in this temporal window. In this case, beam transpori seems to have included more of the differently phased electrons than in the March 20 data with the "doublet" structure.

Verification of the importance of the photocathode material's presence is illustrated in Figs. 3 and 4. In Fig. 3a, the quadrupole focus was adjusted to preserve the PEI electron beamlet pattern from the photocathode on the downstream screen. The same transport then allows the "imaging" of the background emission source distribution in Fig. $3 \mathrm{~b}$ when the drive laser is blocked and higher camera gain is used. The swirling scene on the source (Fig. 3b) may be due partly to machining grooves on the MOLY substrate of the photocathode. Such edges could lead to enhanced local field gradients and, hence, emission of electrons from the lower work-function photocathode Figure 4 shows an even more graphic result of the source before (upper) und after (lower) the photocathode material was baked off the plug. The halo remaining is larger than the plug diameter, and the camern gain had to be increased to see it. The absence of electrons from the central region is evidently because the photocathode material had been removed. Some photocathode material may be on the accelerator cell wall around the plug. The next day we also pulled the PC back about $2 \mathrm{~mm}$ in its slot, and the FE source strength decreased dramatIcally $(10-20)$ with the reduction in rf field.

Subsequently, we performed a cross-comparison of integrated intensities under field-emission 

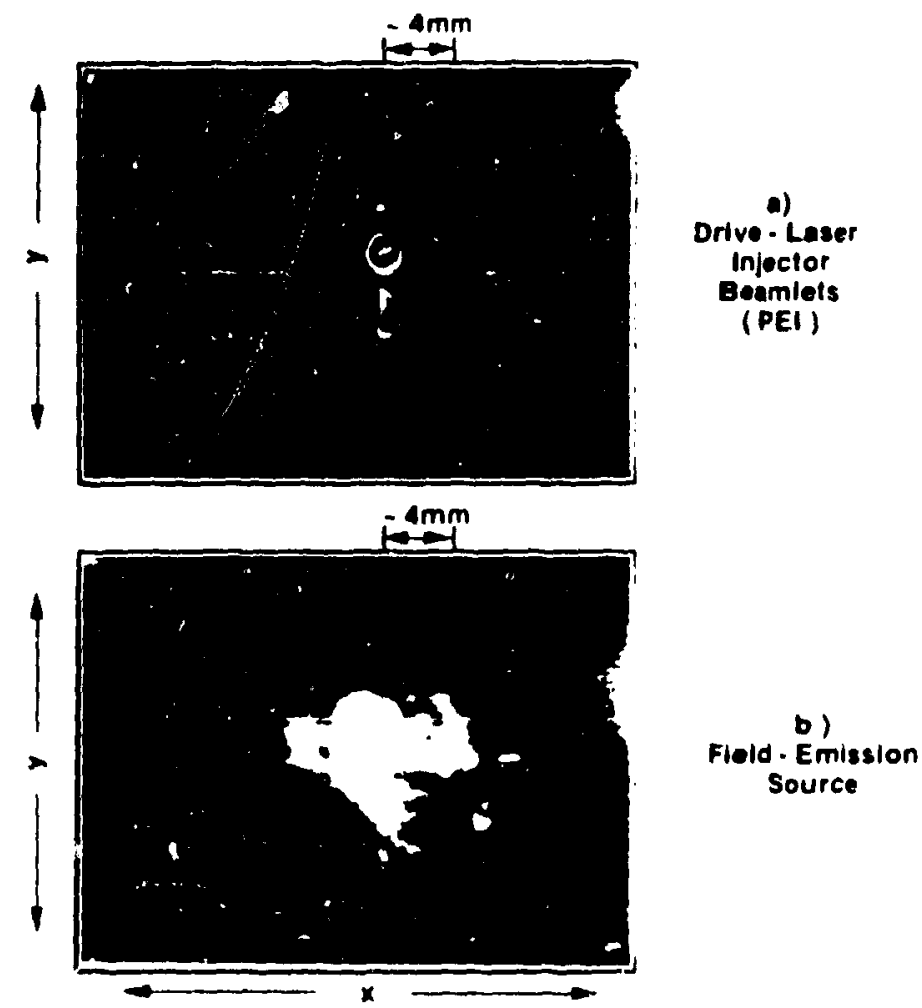

Fig. 3. Beam transport adjusted to preserve (a) PE beamlet pattern and (b) FE source distribution.

electron images and PEI electron-beam spot images beam spot images and referenced the charge via a WCM. This comparison implied the FEI emission source strength of about $2.2 \mathrm{nC}$ per microsecond of if power for a field gradient of $26 \mathrm{MV} / \mathrm{m}$. A plot of FE-electron intensity versus accelerator A field gradient showed an almost exponential dependence. If should be note that one was only measuring those electrons transported through both accelerators and to this particular diagnostic station.

\section{SUMMARY}

In summary, the background source of electrons in our photoinjector has been characterized. These electrons are generated from the photocathode material, depend nonlinearly (exponentially) on the injector accelerator field, depend linearly on the injector accelerat'or feld duration, depend on the mechanical roughness of the photocathode substrate, and had a lemporal extent of tens of picoseconds in our tests. Further experiments are planned at $6 \mathrm{MeV}$ and $-40 \mathrm{MeV}$ on our facility. This phenomenon is surficient in strength 10 inerfere with single micropulse beam parameter studies but not single macropulse studies. if would
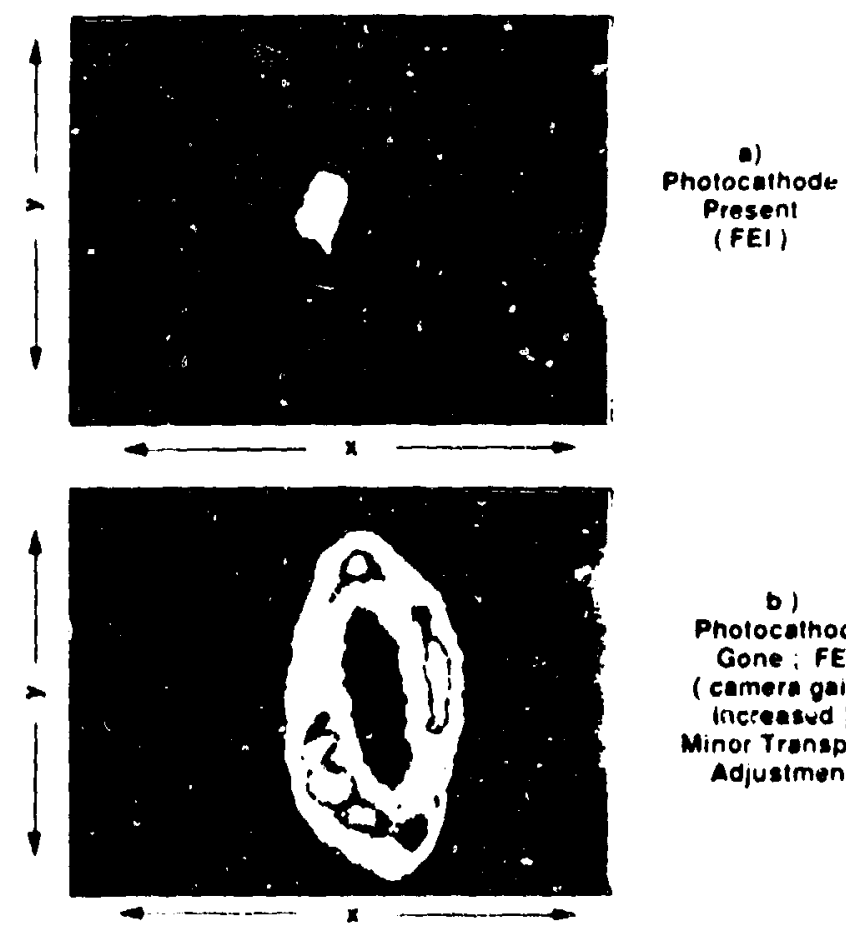

b)

Pholocalnode

Gone : FE

(camera gain

(nereasud)

Minor Tronspon

Adjustment

Fig. 4. Images (via OTR) of the photocathode source (a) before and (b) after bake off of the $\mathrm{CsK}_{2} \mathrm{Sb}$.

need to be addressed in PEI applicaticns with high-duty factor of power.

\section{ACKNOWLEDGMENTS}

The suthor acknowiedges the assistance of i.os Alamo: Nation I Laboratory staff Renee Feldman, Don Feldman, Pat O'Shea, and Scoll Apgar in various aspects of this preliminary work.

\section{REFERENCES}

(1) J. S. Fraser and R. L. Sheffield, IEEE J. of Quant. Elect., Vol. QE-23, n. 1489, September $198 \%$.

(2) A. H. I.umpkin, et al., NIM. A 296, p. 769, 1990.

[3] Alex H. Lumpkin, bruce E. Carlsten, and Renee B. Feldiman, "First Measurements of Electron-Beam Trinsit Time and Micropulse Elongation in a Photoelectric Injector," in Procecdings of the 12th Intermational Flil. Conlerence, Paris, France, Sevtember 17-21. 1990 